\title{
The effect of buildings in floodplain overbank areas
}

\author{
A. D. Parr ${ }^{1} \&$ B. Heatherman ${ }^{2}$ \\ ${ }^{I}$ Department of Civil, Environmental and Architectural Engineering, \\ University of Kansas, Lawrence KS, USA \\ ${ }^{2}$ City of Overland Park Engineering Department, Overland Park KS, \\ USA
}

\begin{abstract}
Urban areas often include inundated areas with a significant number of residential or commercial buildings within the floodplain boundaries. The buildings reduce the conveyance by lowering the cross-sectional area of flow and by creating drag forces. It is important that these factors be considered in floodplain models.

This study considers the resistance effect of buildings in the overbank areas of floodplains. An equation was derived that expresses an effective Manning's $\mathrm{n}$-value as a function of flow, building and roughness parameters.
\end{abstract}

Keywords: n-value, floodplain, overbank, buildings.

\section{Introduction}

Floodplain analysis in urban areas faces the issue of accounting for the resistance created by buildings in the floodplain. Two things happen when impenetrable objects are placed in the floodplain. First, the conveyance of the floodplain is reduced due to the reduction of cross sectional area. Second, the buildings introduce drag forces. Both phenomena will be considered here. An equation is developed to account for both blockage and drag via an effective Manning's nvalue. The HEC-RAS one-dimensional hydraulic model [1] is the model used for most floodplain analysis in the United States. Thus, it will be used herein for demonstration purposes. 


\section{Conveyance reduction due to buildings in the floodplain}

\subsection{Blockage effect}

Manning's equation is defined as

$$
Q=K S^{1 / 2}
$$

And conveyance is given by

$$
K=\left[\frac{1.0 A^{5 / 3}}{n P^{2 / 3}}\right]
$$

where $\mathrm{A}=$ cross sectional area of flow $\left(\mathrm{m}^{2}\right) ; \mathrm{P}=$ wetted perimeter $(\mathrm{m}) ; \mathrm{n}=$ Manning's n-value; $\mathrm{Q}=$ discharge $\left(\mathrm{m}^{3} / \mathrm{s}\right)$; and $\mathrm{S}=$ slope of energy grade line.

Fig. 1 shows an idealized floodplain cross section with a left overbank (LOB), main channel (MC) and right overbank (ROB) regions as shown. If the left overbank has 3 regions with different $n$-values and different widths as shown, the conveyance-weighted Manning's $\mathrm{n}$ for the left overbank (call it $\mathrm{n}_{\mathrm{wl}}$ ) is given by

$$
n_{w l}=\frac{\left[n_{1} K_{1}+n_{2} K_{2}+n_{3} K_{3}\right]}{\left[K_{1}+K_{2}+K_{3}\right]}
$$

(The term $\mathrm{n}_{\mathrm{wl}}$ is called Mann Wtd Left in HEC-RAS Profile Output Tables.)

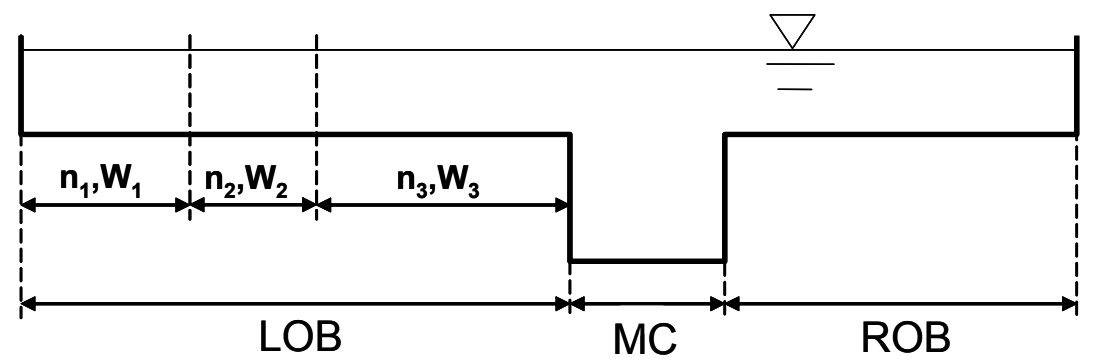

Figure 1: Definition sketch of a floodplain cross section.

The conveyance for a rectangular region of width $\mathrm{W}$ is given by the following equation if sidewall roughness is negligible.

$$
K=\frac{1.0(W y)^{5 / 3}}{n W^{2 / 3}}=\frac{1.0 y^{5 / 3} W}{n}
$$

Assume that the overbank area of the cross section has a constant ground elevation so that $\mathrm{y}$ is constant for the entire overbank. In that case, $1.0 \mathrm{y}^{5 / 3}$ is constant combining Eqs. 3 and 4 gives 


$$
n_{w l}=\frac{\left[W_{1}+W_{2}+W_{3}\right]}{\left[\frac{W_{1}}{n_{1}}+\frac{W_{2}}{n_{2}}+\frac{W_{3}}{n_{3}}\right]}
$$

If one of the three regions in the cross section, say Region 2, is a building of width $\mathrm{W}_{2}$ that is impenetrable, then $\mathrm{n}_{2}=$ infinity and the conveyance of Region 2 is zero. Eq. 5 then becomes

$$
n_{w l}=\frac{\left[W_{1}+W_{2}+W_{3}\right]}{\left[\frac{W_{1}}{n_{1}}+\frac{W_{3}}{n_{3}}\right]}
$$

A simple HEC-RAS project is used here to demonstrate the effect of using large $\mathrm{n}$-values to account for buildings in a floodplain cross section. Fig. 2 shows the cross section where a $10-\mathrm{m}$ wide building is located in the $160-\mathrm{m}$ wide left overbank. Here, an $\mathrm{n}$-value of 10 is used for the building region and the rest of the left overbank has an $n$-value of 0.05. Fig. 3 shows the corresponding HECRAS output table.

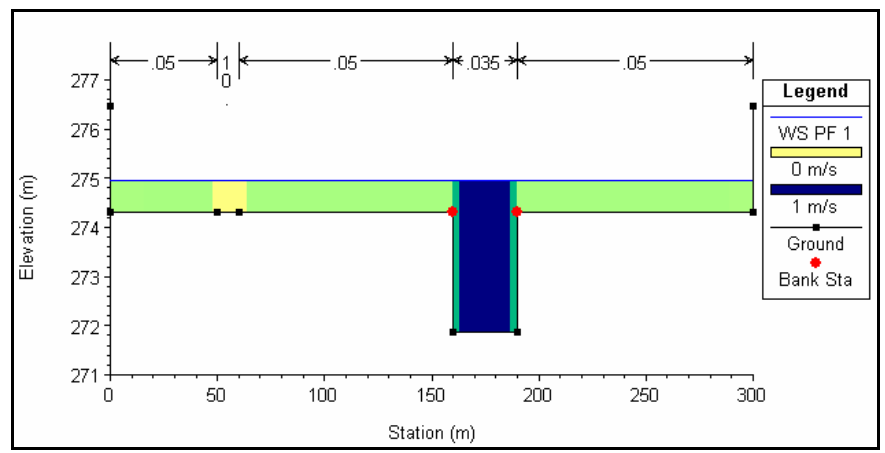

Figure 2: HEC RAS channel with building in LOB.

Fig. 4 shows the conveyance-weighted LOB $n$-value and the LOB conveyance for building $n$-values ranging from 0.05 to 100 for this example. The LOB conveyance was only reduced by $6.7 \%$ when the building $n$-value was increased from 0.05 to 100 . This, of course, corresponds closely to the portion of the left overbank that is blocked by the building $-10 \mathrm{~m} / 160 \mathrm{~m}=0.067$ or $6.7 \%$.

If blockage alone were the criteria used to account for buildings, the overbank $n$-value should be increased by $1 /(1-r)$ where $r$ is the fraction of the cross section blocked by buildings. For a subdivision with 3 houses per $4050 \mathrm{~m}^{2}$ ( 1 acre) and an average house footprint of $200 \mathrm{~m}^{2}\left(2150 \mathrm{ft}^{2}\right), \mathrm{r}=0.15$. The adjusted $\mathrm{n}$-value for an original overbank n-value of 0.050 would be 


\begin{tabular}{|c|c|c|c|c|c|c|}
\hline \multicolumn{6}{|c|}{ Profile Output Table - n value } & $-\mid \square \times$ \\
\hline \multicolumn{7}{|c|}{ File options Sttd. Tables U User Tables Locations ㅂelp } \\
\hline \multicolumn{6}{|c|}{ HEC-RAS Plan: Plan 05 River: nn Reach: nnn Profile: PF 1} & ReloadData \\
\hline \multirow[t]{2}{*}{ Reach } & River Sta & Profile & W.S. Elev 1 & Mann W'd Left & Conv. Left & Conv. Total \\
\hline & & & (m) & & $(\mathrm{m} 3 / \mathrm{s})$ & $(\mathrm{m} 3 / \mathrm{s})$ \\
\hline $\mathrm{nnn}$ & 4 & PF1 & 274.95 & 0.050 & 498.3 & 5066.8 \\
\hline nnn & 3 & PF1 & 274.94 & 0.053 & 1350.2 & 7335.5 \\
\hline $\mathrm{nnn}$ & 2 & PF 1 & 274.93 & 0.050 & 2766.8 & 10500.4 \\
\hline nnn & 1 & PF 1 & 274.93 & 0.050 & 4430.1 & 14200.2 \\
\hline
\end{tabular}

Figure 3: $\quad$ Profile output table for HEC-RAS example.
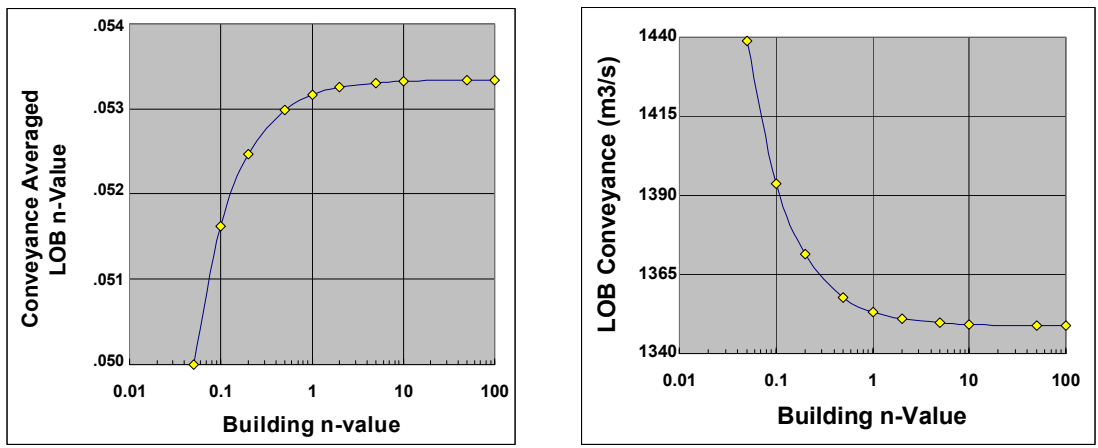

Figure 4: Effect of building n-value on LOB conveyance-weighted n-value and LOB conveyance.

$$
n_{l w}=\frac{n_{l o b}}{(1-r)}=\frac{0.05}{[1-.15]}=0.0588
$$

Residential a commercial areas where GIS coverages are available can be analyzed by assuming $r=A_{B} / A_{T}$, where $A_{B}$ is the total area of the buildings and $A_{T}$ is the total area within the region. Such a region might be a polygon within the polygon n-value coverage used by HEC-GeoRAS. In applying this, however, the n-value polygon should be clipped with an initial floodplain polygon so only within the floodplain is analyzed.

The assumption made herein is that for an overbank area, on average the areal percentage blocked equals the percentage of the average cross section blocked if the buildings are uniformly distributed throughout the total area. (An analogous situation occurs in flow through porous media where the ratio of the volume of voids to the total bulk volume equals the average ratio of the area of pores to the total cross sectional area for a column of the granular material.) 


\subsection{Drag force effect}

In this analysis the buildings will be considered square in shape with the water flowing perpendicular to one of the sides of the building (See Fig. 5). For a water depth of $\mathrm{y}$, the projected area of the house is, therefore, given by $y \sqrt{A_{b}}$ where $A_{b}$ is the footprint area of one house. If a region of length $L$ and width $W$ is considered, the region has a total area of $A_{T}=L W$ and an assumed constant depth of flow, y. Within this area assume there are $m$ houses. Therefore, the total drag force [2] for the $\mathrm{m}$ houses is approximated as

$$
F_{T, D}=C_{D} \frac{\rho Q^{2}}{2 A_{f}^{2}} \sum_{i}^{m}\left(y_{i} \sqrt{A_{b, i}}\right)
$$

where $C_{D}$ is the drag coefficient, $Q=$ total flow through the region, $A_{f}=$ effective cross sectional area of flow and $\rho$ is water density $\left(1 \mathrm{kN} / \mathrm{m}^{3}\right)$.

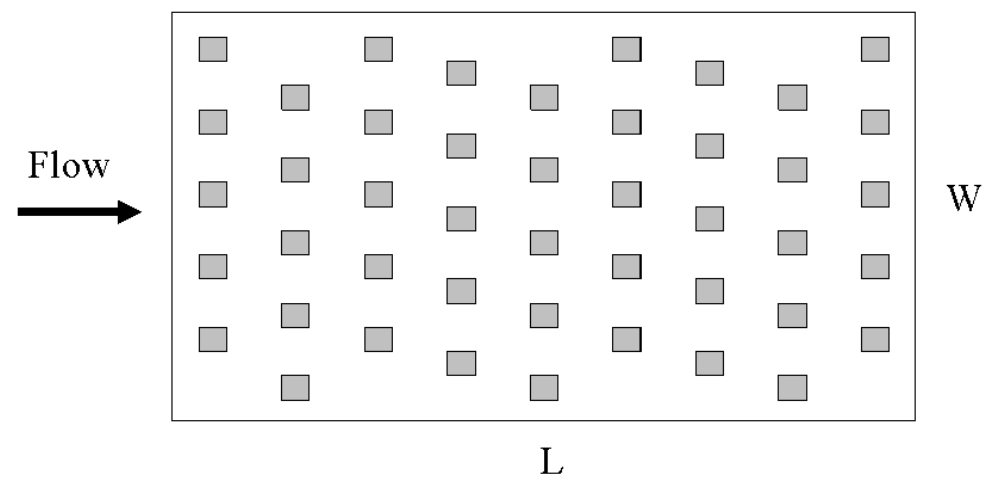

Figure 5: Uniformly distributed building footprints within and area.

Assuming a constant depth y over the region and an effective area of flow equal to (1-r) yW where $r=$ (footprint area of all buildings)/LW, Eq. 8 becomes

$$
\begin{aligned}
& F_{T, D}=C_{D} y\left[\sum\left(\sqrt{A_{b, i}}\right)\right] \frac{\rho Q^{2}}{2(1-r)^{2} y^{2} W^{2}} \\
& =C_{D}\left[\sum\left(\sqrt{A_{b, i}}\right)\right] \frac{\rho Q^{2}}{2(1-r)^{2} y W^{2}}
\end{aligned}
$$

This drag force can be expressed as a shear stress, which can in turn be accounted for by increasing the Manning's n-value in the region.

The total shear force due to frictional resistance is expressed as [2] 


$$
F_{f}=\tau W L=\gamma R S=\gamma\left[\frac{y W}{W}\right] \frac{L W n^{2} Q^{2} W^{4 / 3}}{y^{10 / 3} W^{10 / 3}}
$$

where $\tau=$ bed shear stress, $\gamma=\rho g=$ specific weight of water $=9.81 \mathrm{kN} / \mathrm{m}^{3}, \mathrm{~S}=$ slope of energy grade line. Eq. 10 can expressed as

$$
F_{f}=\beta \mathrm{n}^{2}
$$

where

$$
\beta=\frac{\gamma L Q^{2}}{y^{7 / 3} W}
$$

The total force, $\mathrm{F}_{\mathrm{T}}$, includes the bed friction plus the form drag due to the buildings. Expressing the total force as a shear force using the form given in Eq. 11 results in,

$$
\begin{gathered}
F_{T}=\beta \mathrm{n}_{*}^{2}=\beta \mathrm{n}^{2}+C_{D}\left[\sum\left(\sqrt{A_{b, i}}\right)\right] \frac{\rho Q^{2}}{2(1-r)^{2} y W^{2}} \\
\mathrm{n}_{*}^{2}=\mathrm{n}^{2}+\left[\frac{1}{\beta}\right] C_{D}\left[\sum\left(\sqrt{A_{b, i}}\right)\right] \frac{\rho Q^{2}}{2(1-r)^{2} y W^{2}} \\
=\mathrm{n}^{2}+\left[\frac{y^{7 / 3} W}{\gamma L Q^{2}}\right] C_{D}\left[\sum\left(\sqrt{A_{b, i}}\right)\right] \frac{\rho Q^{2}}{2(1-r)^{2} y W^{2}}
\end{gathered}
$$

Rearranging gives

$$
\mathrm{n}_{*}=\sqrt{\mathrm{n}^{2}+\left[\frac{C_{D}\left[\sum\left(\sqrt{A_{b, i}}\right)\right] y^{4 / 3}}{2 g W L(1-r)^{2}}\right]}
$$

where $\mathrm{n}_{*}$ is the effective $\mathrm{n}$-value corrected for drag effects. Letting $\mathrm{A}_{\mathrm{T}}=\mathrm{WL}$, Eq. 15 becomes.

$$
\mathrm{n}_{*}=\sqrt{\mathrm{n}^{2}+\left[\frac{C_{D}\left[\sum\left(\sqrt{A_{b, i}}\right)\right] y^{4 / 3}}{2 g A_{T}(1-r)^{2}}\right]}
$$


Finally, incorporating Eq. 7 for the blockage effect gives an equation accounting for both drag and reduction in cross sectional area.

$$
\mathrm{n}_{*}=\sqrt{\frac{\mathrm{n}^{2}}{(1-r)^{2}}+\left[\frac{C_{D}\left[\sum\left(\sqrt{A_{b, i}}\right)\right] y^{4 / 3}}{2 g A_{T}(1-r)^{2}}\right]}
$$

where $y=$ mean depth in region, $r=($ total footprint areas of buildings $) /($ total area of region), $C_{D}=2.0$ for blocks, $g=9.81 \mathrm{~m}^{2} / \mathrm{s}$, and $\mathrm{y}=$ average depth of flow in region. To apply Eqs. 16 or 17 a new field containing the square root of the building areas would be created in the building coverage within ARC View or ARC Info.

\subsection{Combined example}

Eq. 17 can be simplified in order to create some plots to see the overall effect of blockage and drag force. If all the buildings are assumed to be of the same size, $A_{b}$, the summation term can be written as follows

$$
\sum\left(\sqrt{A_{b, i}}\right)=m \sqrt{A_{b}}=\frac{A_{B}}{A_{b}} \sqrt{A_{b}}=\frac{r A_{T}}{A_{b}} \sqrt{A_{b}}=\frac{r A_{T}}{\sqrt{A_{b}}}
$$

where $A_{B}=$ total area of buildings and $m=$ number of buildings. Substituting Eq. 18 into Eq. 17 and rearranging gives the following

$$
\mathrm{n}_{*}=\frac{1}{(1-r)} \sqrt{\mathrm{n}^{2}+\left[\frac{C_{D} r y^{4 / 3}}{2 g \sqrt{A_{b}}}\right]}
$$

Eq. 19 is plotted in Fig. 6 for an original n-value of $0.05, C_{D}=2$ and an average house footprint area of $200 \mathrm{~m}^{2}$. The range of flow depth is from 0.001 to $2 \mathrm{~m}$ and the range of $r$ is 0 to 0.4 .

When drag force effects are not considered Eq. 20 takes the same form as Eq. 7 and becomes

$$
\mathrm{n}_{*}=\frac{n}{(1-r)}
$$

This equation is independent of depth, y. Fig. 7 shows a plot of Eq. 20 for $\mathrm{n}=$ 0.050 for a range of $r$-values from 0 to 0.4 . 


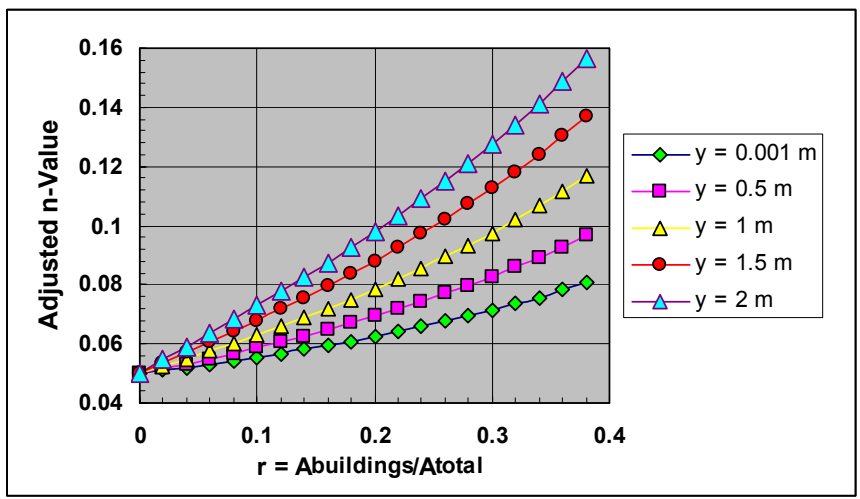

Figure 6: $\quad$ Eq. 19 for $\mathrm{C}_{\mathrm{D}}=2$.

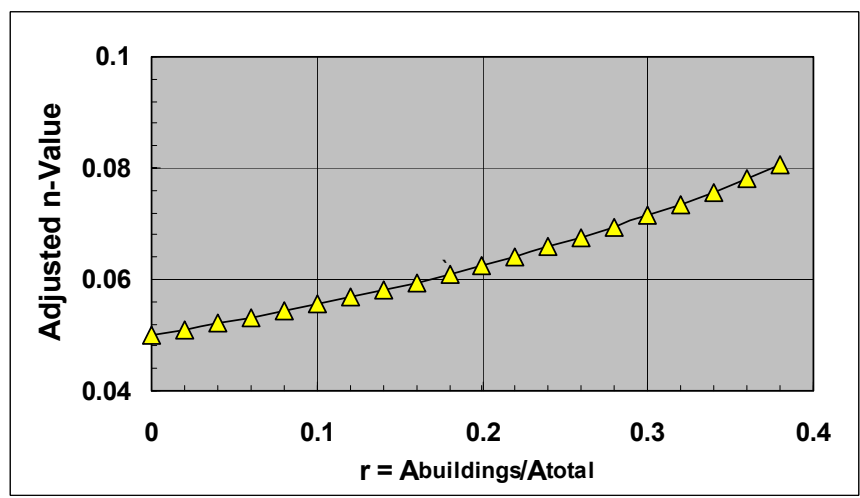

Figure 7: $\quad$ Eq. 20 or Eq. 19 with $\mathrm{C}_{\mathrm{D}}=0$.

\section{Conclusions}

A method was developed to account for conveyance reduction due to both blockage and drag forces introduced by buildings in a floodplain. The effects of these phenomena were accounted for by increasing the original Manning's nvalue to an effective n-value. Many simplifying assumptions were made in the analysis. Also, the application of the drag force equation did not consider the possibility of shielding of a building by other upstream buildings.

Application of the equations presented herein requires engineering judgement. Fig. 8 shows a GIS coverage of an urban subdivision where several residences are in the floodplain. Those houses are shaded black. In this case, the flow is perpendicular to the rows of houses and the rows are close together. Consequently, the effective n-value from Eq. 19 is probably too low since it assumes uniformly distributed buildings. In other situations, the rows of 
buildings may be aligned with the flow and the effective n-value from Eq. 19 would probably be too high.

More refined methods could be developed using the velocity and depth grids generated by the postRAS extension of HEC-GeoRAS [3] and using individual building footprint dimensions.

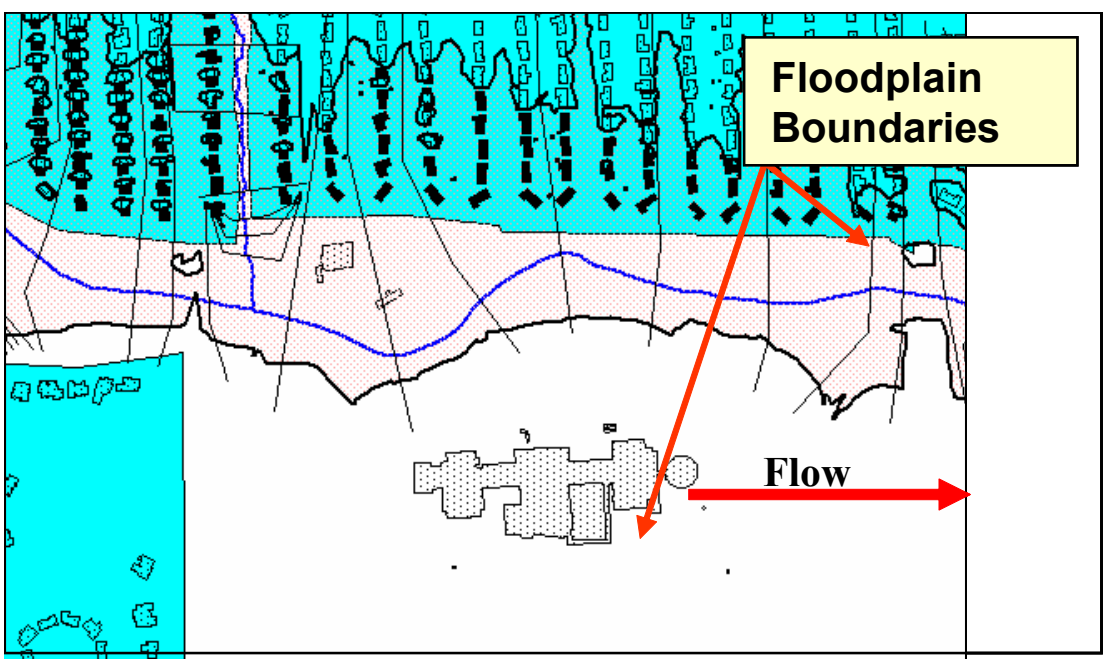

Figure 8: GIS coverage showing houses in a floodplain.

\section{Acknowledgements}

This project was supported by the Johnson County (Kansas) Stormwater Program. Special thanks are due to Mr. Kent Lage and Mr. Chet Belcher for their support in this endeavor.

\section{References}

[1] Brunner, G. W., HEC-RAS, River Analysis System User's Manual, US Army Corps of Engineers Hydrologic Engineering Center (HEC), Davis CA, USA, 2002.

[2] Henderson, F.M., Open Channel Flow, The Macmillan Company, NY, pp 66-88, 1966.

[3] Ackerman, C.T., HEC-GeoRAS, An Extension for Support of HEC-RAS Using ArcView GIS, US Army Corps of Engineers Hydrologic Engineering Center (HEC), Davis CA, USA, 2002. 